\title{
The Effects of Curtain Airbag on Occupant Kinematics and Injury Index in Rollover Crash
}

\author{
Hongyun Li, ${ }^{1,2}$ Chengyue Jiang $\mathbb{D}^{2},{ }^{2}$ Dong Cui, ${ }^{1}$ and Shuang Lu ${ }^{1}$ \\ ${ }^{1}$ China Automotive Technology and Research Center, Tianjin 300300, China \\ ${ }^{2}$ Key Laboratory of Advanced Manufacture Technology for Automobile Parts, Ministry of Education, Chongqing University of \\ Technology, Chongqing 400054, China
}

Correspondence should be addressed to Chengyue Jiang; jiangchengyue@cqut.edu.cn

Received 8 December 2017; Revised 10 February 2018; Accepted 21 February 2018; Published 22 March 2018

Academic Editor: Yong Peng

Copyright (c) 2018 Hongyun $\mathrm{Li}$ et al. This is an open access article distributed under the Creative Commons Attribution License, which permits unrestricted use, distribution, and reproduction in any medium, provided the original work is properly cited.

Background. Occupant injuries in rollover crashes are associated with vehicle structural performance, as well as the restraint system design. For a better understanding of the occupant kinematics and injury index in certain rollover crash, it is essential to carry out dynamic vehicle rollover simulation with dummy included. Objective. This study focused on effects of curtain airbag (CAB) parameters on occupant kinematics and injury indexes in a rollover crash. Besides, optimized parameters of the CAB were proposed for the purpose of decreasing the occupant injuries in such rollover scenario. Method and Material. The vehicle motion from the physical test was introduced as the input for the numerical simulation, and the 50\% Hybrid III dummy model from the MADYMO database was imported into a simulation model. The restraint system, including a validated CAB module, was introduced for occupant kinematics simulation and injury evaluation. TTF setting, maximum inflator pressure, and protection area of the $\mathrm{CAB}$ were analysed. Results. After introducing the curtain airbag, the maximum head acceleration was reduced from $91.60 \mathrm{~g}$ to $49.52 \mathrm{~g}$, and the neck $\mathrm{M}_{\mathrm{x}}$ and neck $\mathrm{F}_{\mathrm{z}}$ were reduced significantly. Among these CAB parameters, the TTF setting had the largest effect on the head acceleration which could reduce $8.6 \mathrm{~g}$ furthermore after optimization. The neck $\mathrm{F}_{z}$ was decreased from $3766.48 \mathrm{~N}$ to $2571.77 \mathrm{~N}$ after optimization of CAB protection area. Conclusions. Avoiding hard contact is critical for the occupant protection in the rollover crashes. The simulation results indicated that occupant kinematics and certain injury indexes were improved with the help of CAB in such rollover scenario. Appropriate TTF setting and inflator selection could benefit occupant kinematics and injury indexes. Besides, it was advised to optimize the curtain airbag thickness around the head contact area to improve head and neck injury indexes.

\section{Introduction}

Among all types of vehicle accidents, rollover crashes are the most complex and least understood [1]. Rollover crashes are associated with approximately $20 \%$ of all fatal crashes in the United States [2]. While in China, the rollover crashes constitute about $2.7 \%$ of all crashes but account for approximately $5.6 \%$ of the fatal crashes [3]. In recent years, Chinese automakers continue to gain share in the domestic market, especially in the sport utility vehicle (SUV) segment. According to statistics, SUVs accounted for $36 \%$ in all sales of Chinese passenger vehicle market in 2016 [4]. However, SUVs are more likely to suffer the rollover crashes due to their higher rollover stability factor, which is related to the track width and the height of the centre of gravity. Thus, it is important to understand certain SUV's rollover characteristics and the interaction between occupants and vehicle compartment.

Although the rollover crash causes high fatalities relative to its occurrence, there is no repeatable standardized dynamic rollover test procedure due to the chaotic nature of rollover crash [5]. Some previous physical tests and computer simulation studies were carried out to understand the mechanisms of such crash. In the research of Grzebieta et al. [6], it was concluded that to date the current test protocols were not capable of consistently replicating the injuries identified in real-world rollover crashes. Heller et al. [7] carried out two rollover tests utilizing instrumented 


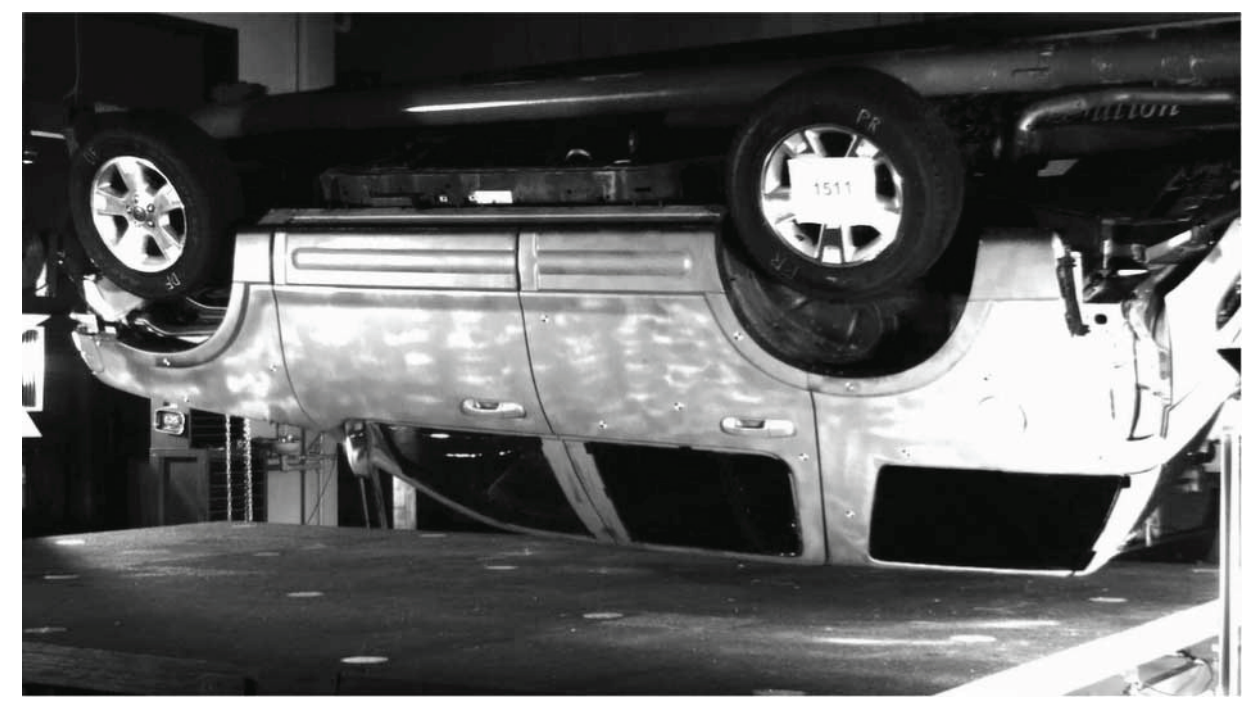

Figure 1: Rollover test at the moment of vehicle to ground contact.

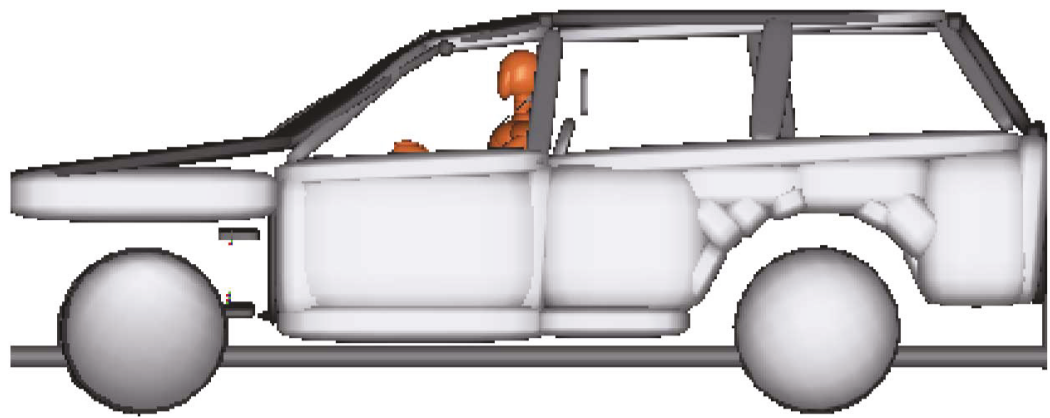

(a) Side view

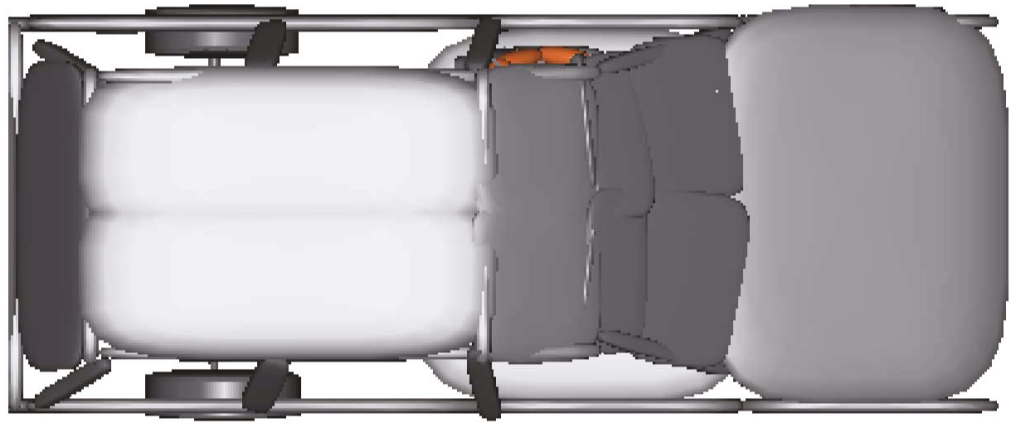

(b) Top view

FIGURE 2: Rollover simulation model with Hybrid III dummy model.

test vehicles and instrumented ATDs to investigate occupant kinematics and injury response throughout the entire rollover sequences, in which the occupant's upper neck compressive loading was more than $4000 \mathrm{~N}$ in the sedan due to the head-to-vehicle and head-to-ground contact. Han and Seo [8] developed a finite element-based numerical vehicle simulation model consisting of a rigid lower body and a deformable upper body and addressed essential factors to improve the rollover performance. Jiang et al. [9] demonstrated the applicability of occupant kinematics simulation and head injury analysis with MADYMO simulation for rollover cases, including two real-world rollover crashes, together with an SAEJ2114 rollover test, which concluded that more real-world rollover crashes need replicating and simulating. Recent studies of restrained occupants involved in single-vehicle pure rollover crashes that occurred in the United States by Mattos et al. [10] and Bambach et al. [11] indicated that serious injuries to the thorax, head, 

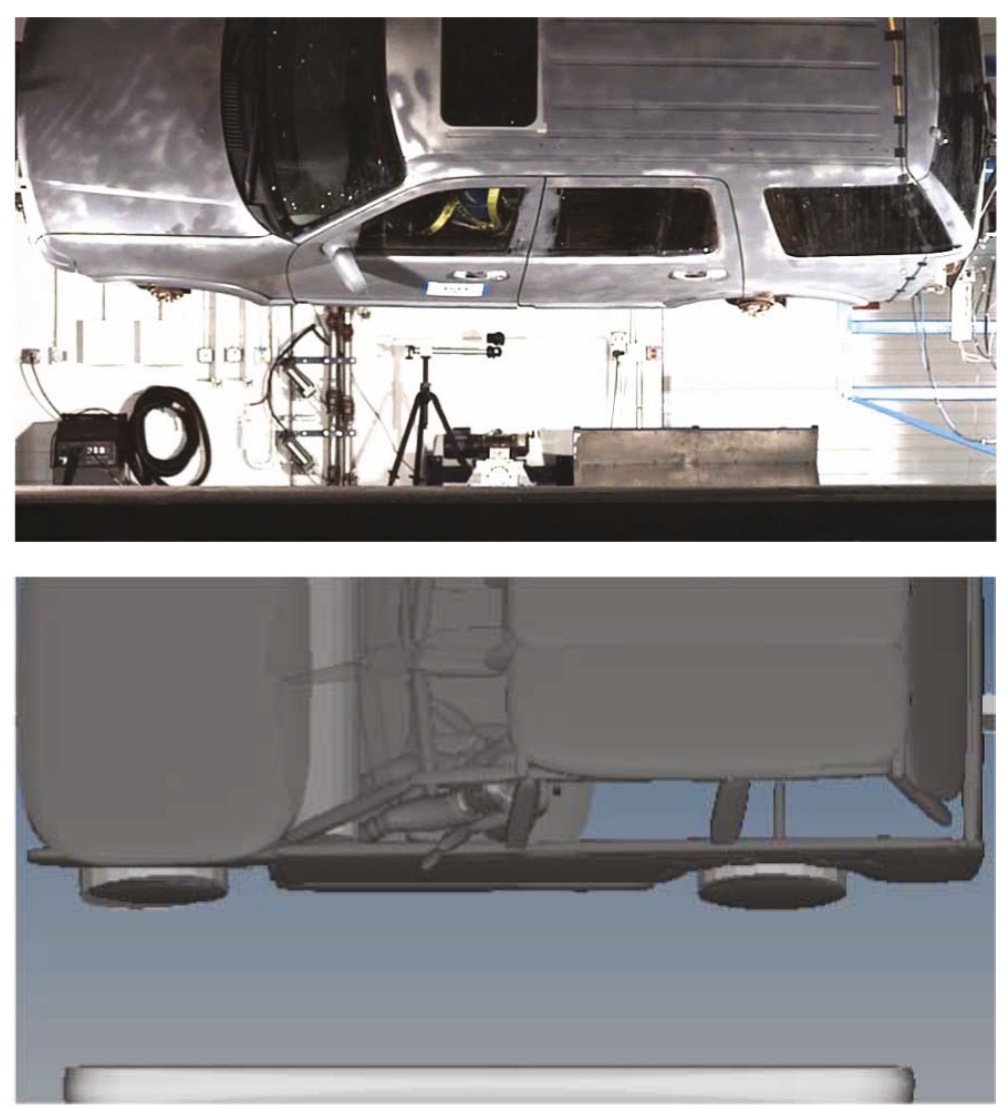

(a) $500 \mathrm{~ms}$
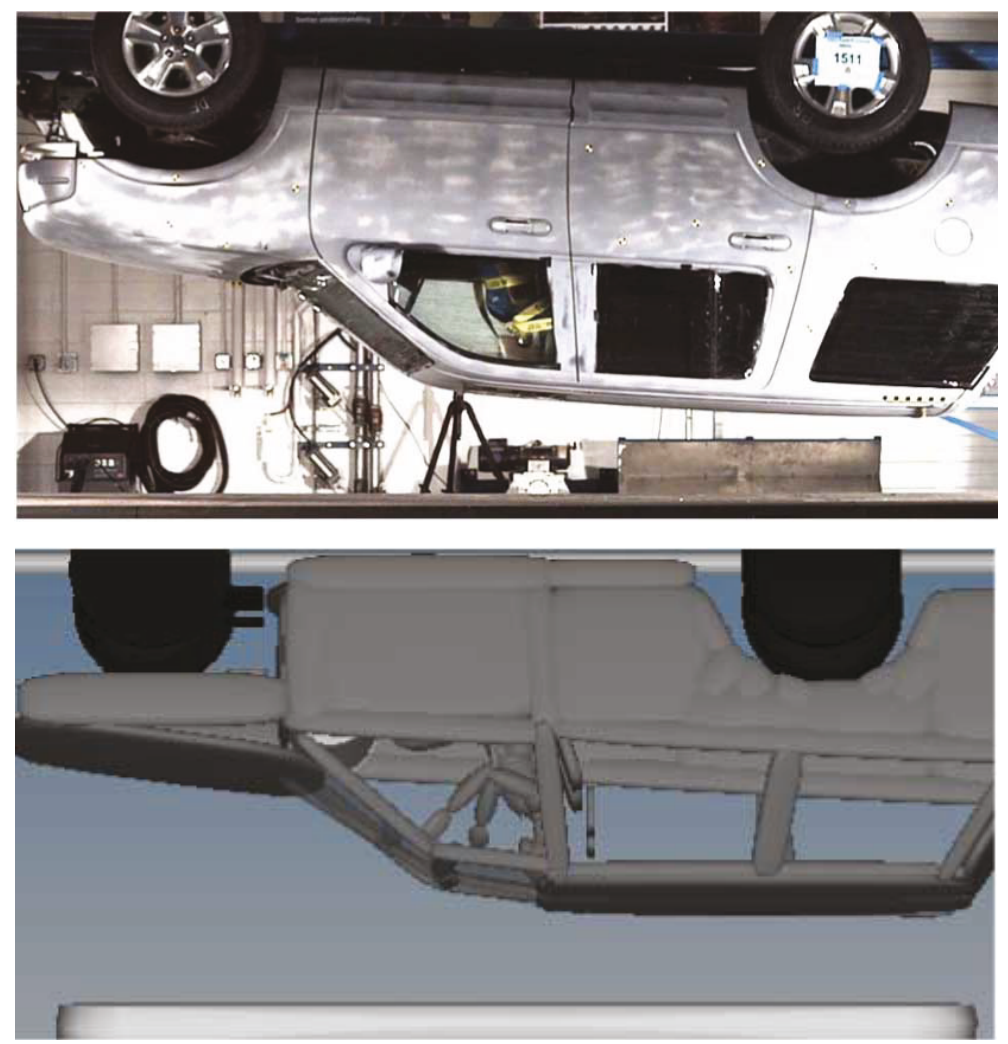

(b) $1000 \mathrm{~ms}$

Figure 3: Continued 

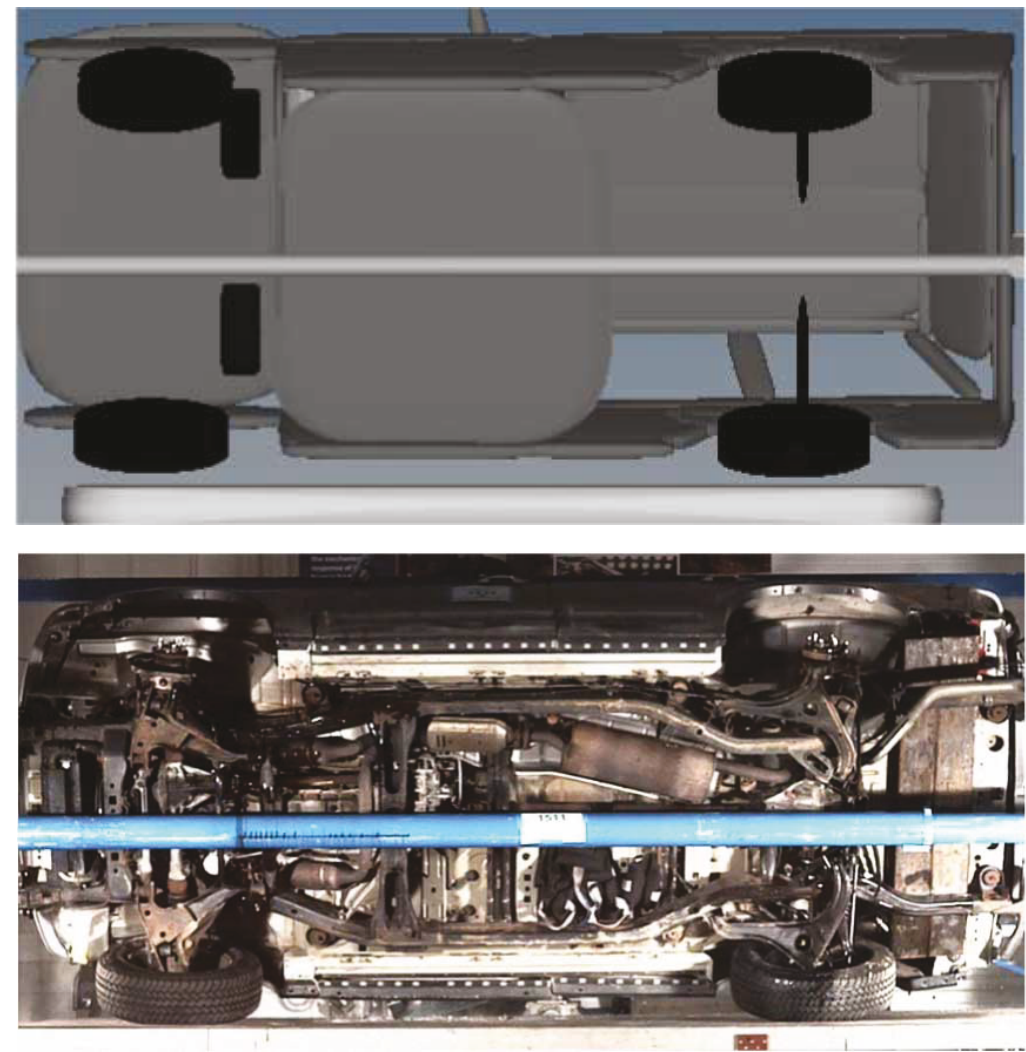

(c) $1500 \mathrm{~ms}$

FIGURE 3: Vehicle rollover trajectory correlation.

and spine could still occur even when there is little or no roof crash, highlighting the need to improve occupant safety systems.

Improving the occupant safety in rollover is challenging due to the different types of rollover crashes. The rollover curtain airbag (CAB) was first introduced in the United States automotive market in 2002 for the purpose of providing incremental benefit to belted occupants in rollover crashes [12]. It is known from crash testing and data analysis that the curtain airbags provide considerable benefit to occupants in rollover crashes $[12,13]$.

For more detailed analysis, it is critical to perform computer simulations to understand the interactions between belted occupants and curtain airbags during a certain SUV rollover crash scenario. In this paper, a multibody dynamic rollover model was developed according to a rollover test. After validation, the effects of certain curtain airbag parameters on occupant protection performance in such rollover crash were evaluated.

\section{Method}

This study focused on the simulation of vehicle dynamic rollover, as well as the assessment of curtain airbag parameters. A multibody rollover simulation model, including rigid vehicle chassis and occupant compartment model, was built and validated with a dynamic rollover test from the University of Virginia. Based on the correlated vehicle model, the 50\% Hybrid III dummy model from the MADYMO database [14] was imported for the occupant kinematics simulation.

To evaluate the effects of $\mathrm{CAB}$ on both occupant kinematics and injury index, a validated $C A B$ module from side impact was included in the simulation model for further injury evaluation. The effects of certain $\mathrm{CAB}$ parameters, including TTF setting, inflator pressure, and CAB protection area, upon occupant protection performance, were evaluated.

2.1. Rollover Test and Modeling. So far, the dynamic rollover test system in the University of Virginia [15] is one of the test rigs that may be capable of repeatable rollover test. For the following vehicle rollover simulation, a dynamic rollover test carried out by the University of Virginia was introduced in this study. In this rollover test, the vehicle rotational motion and drop height were controlled. The scenario of the rollover test is shown in Figure 1.

The original vehicle FE model used for modeling in this paper was developed at the National Crash Analysis Center (NCAC) [16], which was validated to several subsystem tests and two FMVSS No. 216 quasistatic tests. To reduce the computation time, a multibody rollover simulation model, including rigid vehicle chassis and occupant compartment, was built for the following analysis. The major components of the vehicle model were positioned according to the vehicle FE model. A 50\% Hybrid 


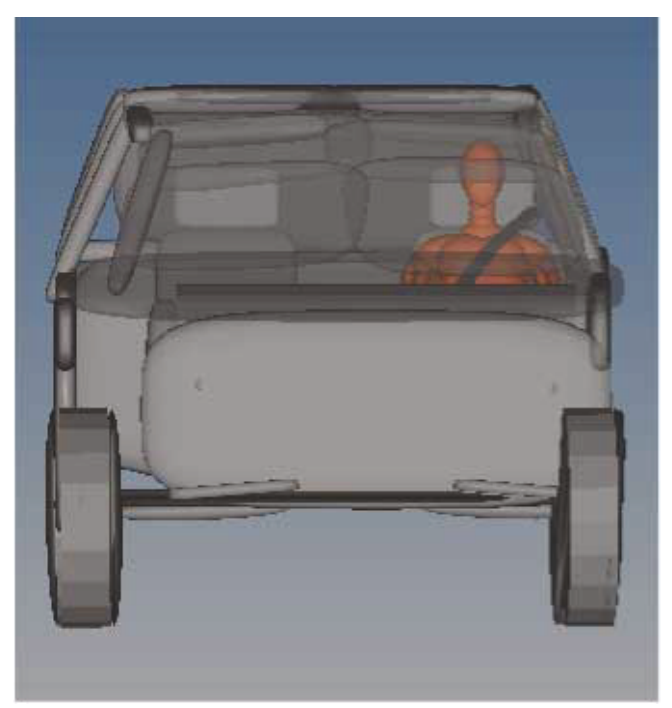

(a) $0 \mathrm{~ms}$

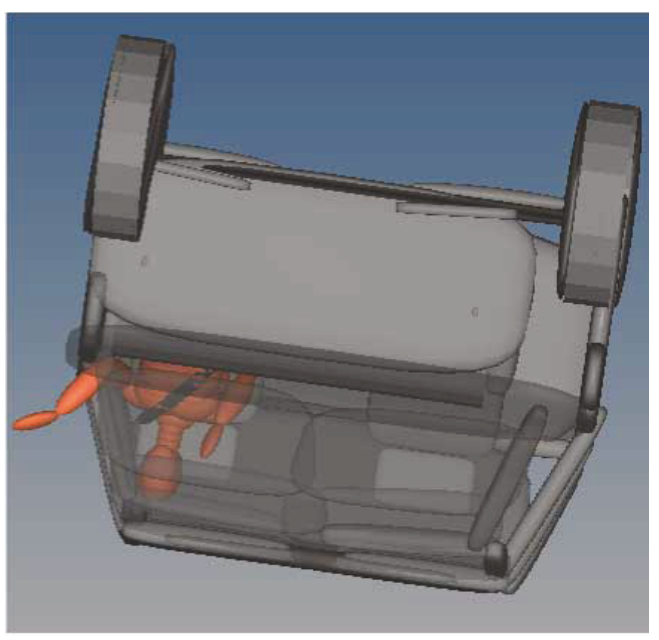

(c) $1000 \mathrm{~ms}$

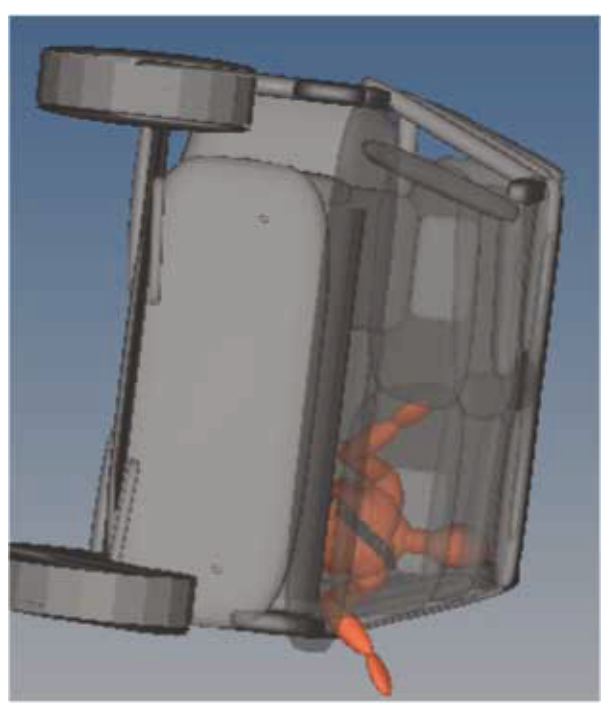

(b) $500 \mathrm{~ms}$

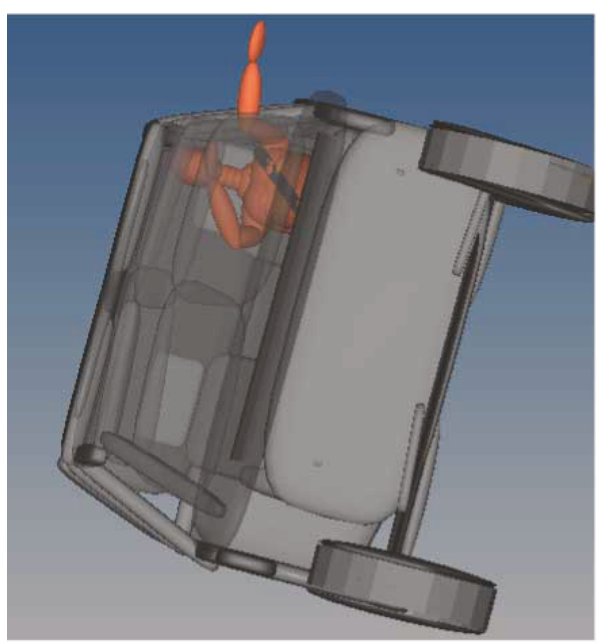

(d) $1500 \mathrm{~ms}$

FIGURE 4: Occupant kinematics in rollover simulation.

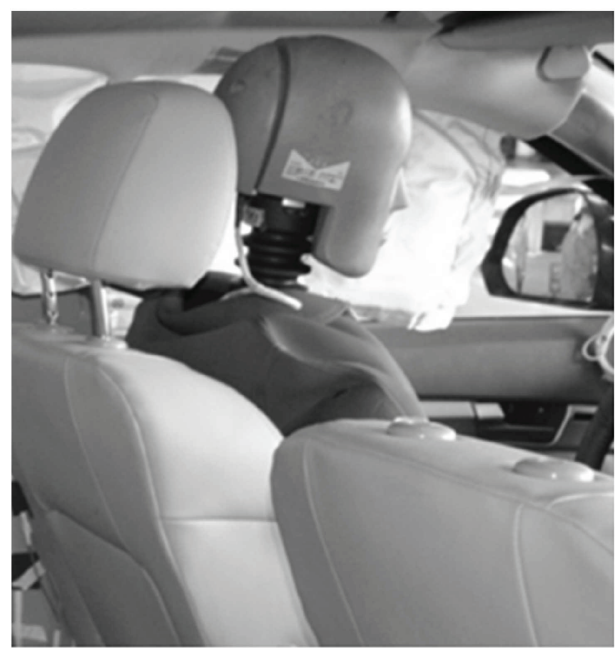

(a) Curtain airbag in test

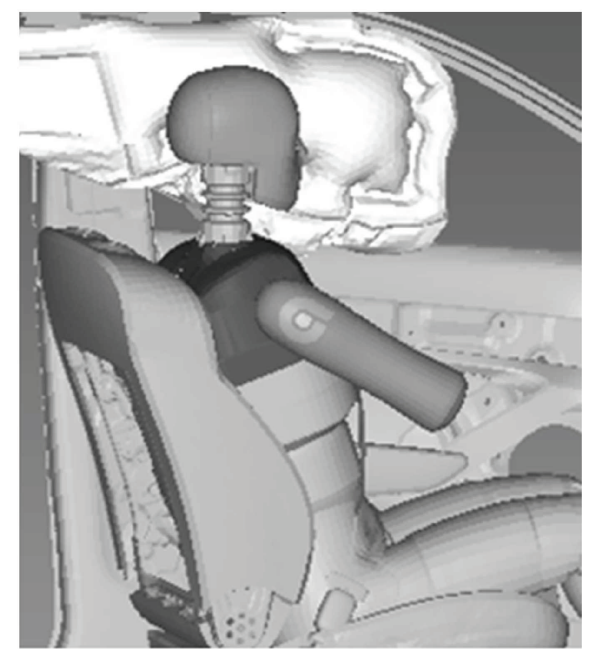

(b) Curtain airbag in simulation

Figure 5: Curtain airbag in the test and simulation. 


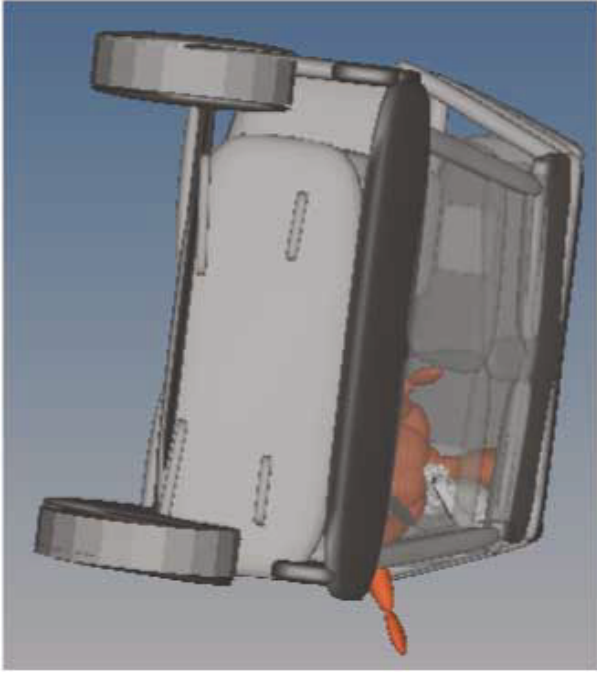

(a) $500 \mathrm{~ms}$

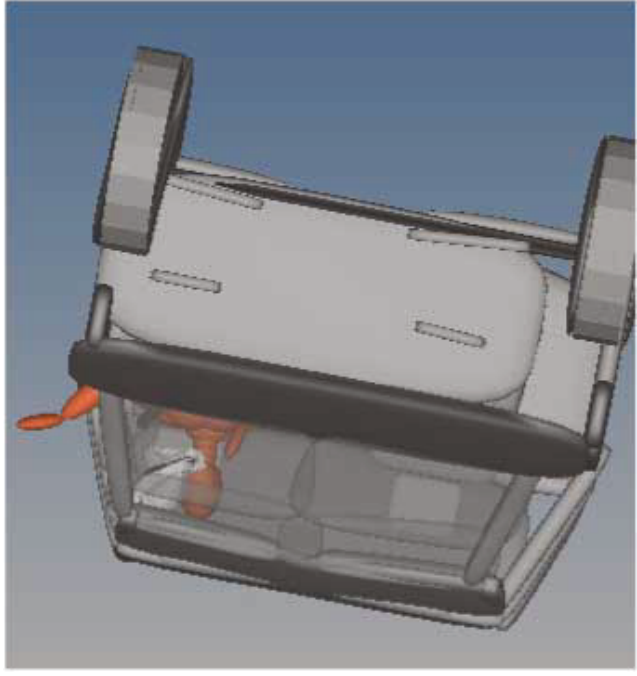

(b) $1000 \mathrm{~ms}$

FIGURE 6: Occupant kinematics with curtain airbag in rollover simulation.

III dummy model from the MADYMO database was imported for the occupant kinematics simulation and injury evaluation. The occupant model was belted with both shoulder belt and lap belt. The whole simulation model is shown in Figure 2.

The initial settings of the physical rollover test were introduced as the input and boundary conditions for the numerical simulation. The vehicle motion in the simulation was defined by prescribing the motion for a free joint at the vehicle center of gravity (COG) with all degrees of freedom. The restraints for the vehicle, as the main parameters affecting the vehicle rollover simulation results, were set according to the test information. The initial roll velocity was $190^{\circ} / \mathrm{s}$, and the test bed speed was $24 \mathrm{~km} / \mathrm{h}$.

2.2. Rollover Model Validation. The validation of rollover simulation model was carried out by comparing the vehicle trajectory from the simulation with that of the test. As shown in Figure 3, the vehicle trajectory of simulation correlated well with that of the rollover test. The simulation result indicated that the vehicle roof made contact with the test bed at similar angle with that of the test.

2.3. Occupant Kinematics Simulation. To simulate the occupant kinematics in such rollover scenario, a 50\% Hybrid III dummy model from the MADYMO database was placed at the driver position. The occupant compartment was built according to the geometry of the vehicle, which included instrument panel, seat, and FE seat belts. The component contact stiffness was mainly from the component test and MADYMO example case, as in the research of [17].

The occupant kinematics of the simulation from $0 \mathrm{~ms}$ to $1500 \mathrm{~ms}$ was shown in Figure 4. It was found that the left arm of the occupant was ejected around $300 \mathrm{~ms}$. Besides, the occupant's head made contact with the vehicle interior around $1090 \mathrm{~ms}$. This was similar to the finding of Huelke et al. [18], who indicated that $33 \%$ head injuries resulted from

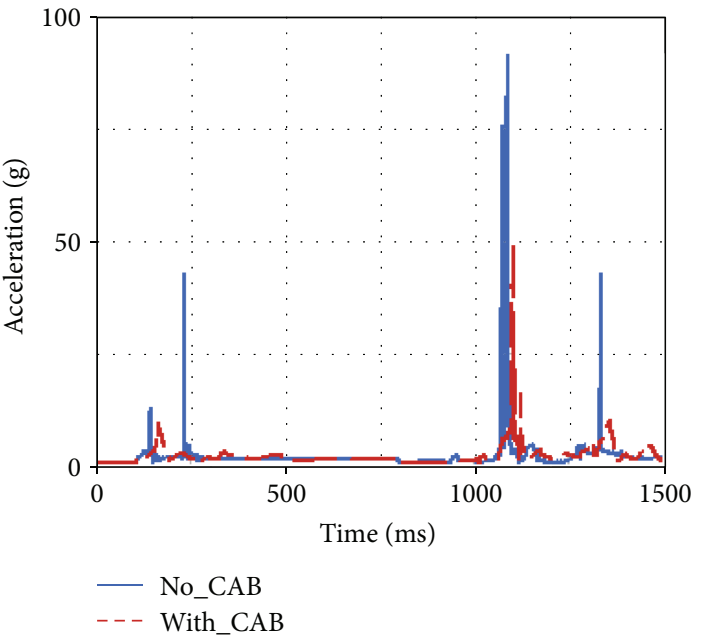

Figure 7: Head resultant accelerations.

contact to vehicle interior surfaces. Furthermore, the contact between the head and vehicle resulted in the $5892.44 \mathrm{~N}$ neck $F_{z}$, which corresponded to the research result of Heller et al. [7]. Heller et al. found that the occupant's upper neck compressive loading was more than $4000 \mathrm{~N}$ in the sedan due to the head-to-vehicle contact.

Thus, further attention was paid on how to reduce such hard contact and improve the injury index in the following study.

2.4. Curtain Airbag (CAB) Model. The curtain airbag was firstly invented to protect the occupants during side impacts and rollover crashes. In case of the rollover crashes, introducing the curtain airbag could help mitigate the occupant ejection $[19,20]$.

The main objective of this study is to evaluate the effects of curtain airbag on occupant kinematics and injury indexes. 


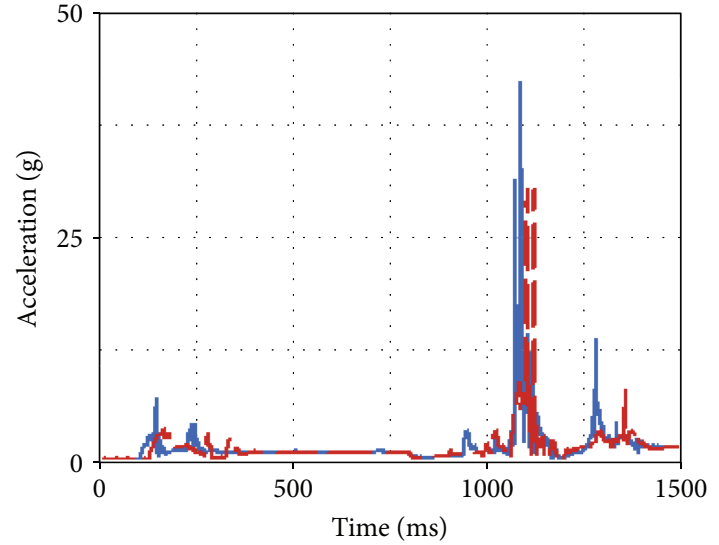

- No_CAB

- - With CAB

Figure 8: Chest resultant accelerations.

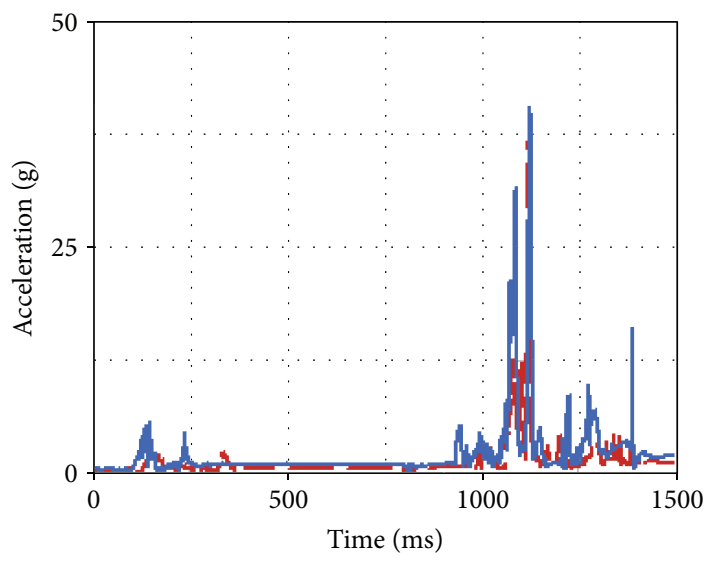

- No_CAB

--- With_CAB

Figure 9: Pelvis resultant accelerations.

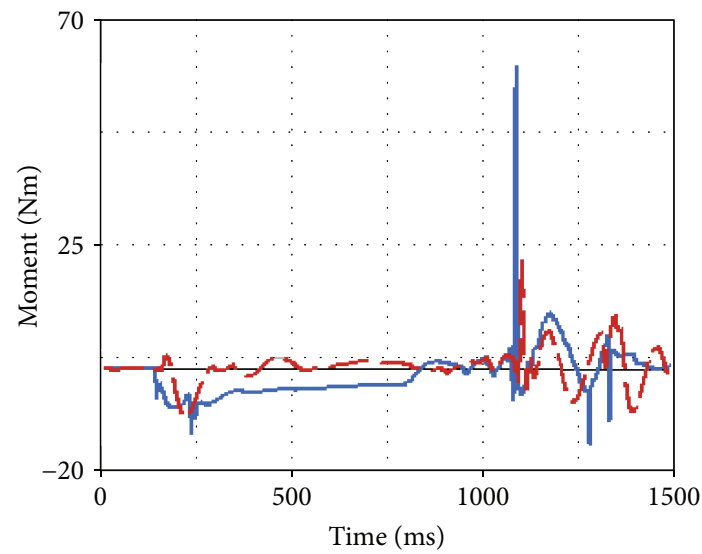

- No CAB

- - - With CAB

FIgURE 10: Upper neck $\mathrm{M}_{\mathrm{x}}$

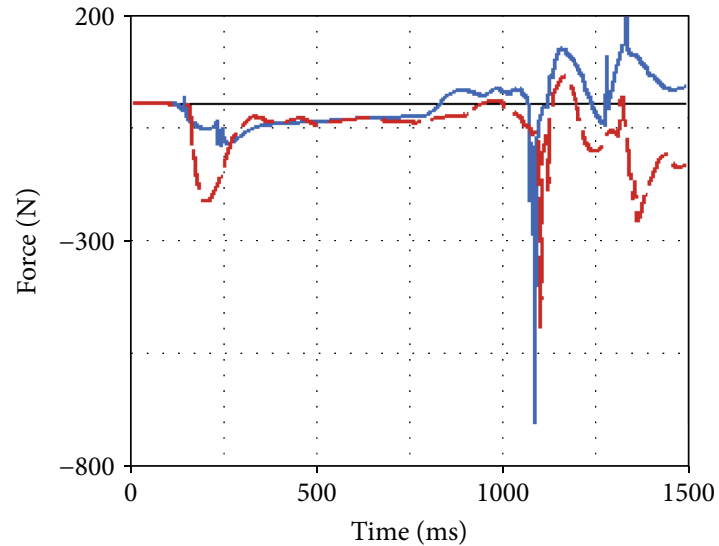

- No_CAB

- - With $\mathrm{CAB}$

FIgURE 11: Upper neck $\mathrm{F}_{\mathrm{y}}$

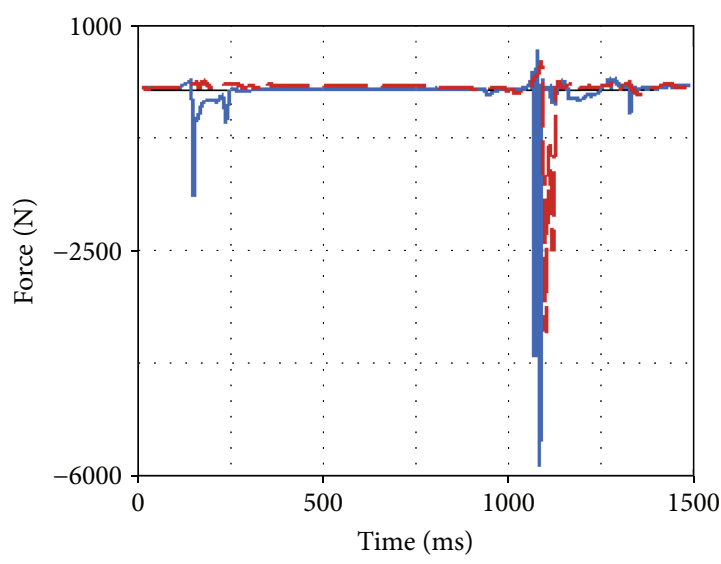

- No_CAB

-- - With_CAB

FIGURE 12: Upper neck $\mathrm{F}_{\mathrm{z}}$

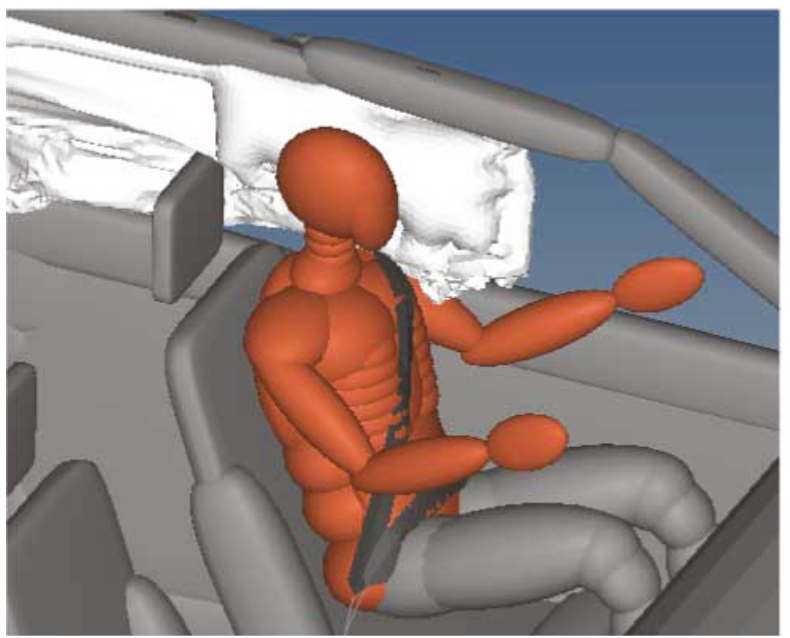

FIgURE 13: Contact between the head and curtain airbag at $225 \mathrm{~ms}$. 
TABLE 1: Occupant injury indexes with different CAB TTFs.

\begin{tabular}{lcccccc}
\hline Number & CAB TTF $(\mathrm{ms})$ & Head acceleration $(\mathrm{g})$ & Chest acceleration $(\mathrm{g})$ & $\mathrm{Neck} \mathrm{F}_{\mathrm{y}}(\mathrm{N})$ & $\mathrm{Neck}_{\mathrm{z}}(\mathrm{N})$ & $\mathrm{Neck} \mathrm{M}$ \\
\hline CASE1 & 120 & 40.91 & 25.39 & -408.44 & -3071.07 & 14.19 \\
CASE2 & 150 & 49.52 & 30.51 & -492.57 & -3766.48 & 22.08 \\
CASE3 & 180 & 52.34 & 31.69 & -522.54 & -4382.55 & 28.73 \\
\hline
\end{tabular}

Thus, a curtain airbag which was validated in certain side impact simulation was imported for further analysis in this study, as shown in Figure 5. The curtain airbag geometry and inflator data were from the supplier.

To analyze the effects of curtain airbag on occupant kinematics and injury index, the CAB model above was imported to the rollover simulation model and installed around the roof rail area.

\section{Simulation Results and Injury Analysis}

3.1. Occupant Kinematics with $C A B$. After introducing the curtain airbag, the occupant kinematics at $500 \mathrm{~ms}$ and $1000 \mathrm{~ms}$ was shown in Figure 6.

From Figure 6, it was found that introducing the curtain airbag could help to keep the head of the occupant in the passenger compartment during the whole rollover simulation, and the contact force between the head and vehicle interior was decreased. However, the left arm of the occupant was still ejected around $300 \mathrm{~ms}$.

3.2. Occupant Injuries with $C A B$. Occupant injuries of both With-CAB case and No-CAB case were shown in Figures 7-12. The injury index curve of the No-CAB case is the blue line, while the curve of the With-CAB case is the red line.

As shown in Figures 7-9, both head resultant acceleration and chest resultant acceleration were reduced when the $\mathrm{CAB}$ was applied in vehicle during such rollover simulation, while the pelvis resultant acceleration was almost the same. It was obvious that the CAB mainly affected the head and chest regions, and it had little influence on the pelvis. This finding was similar to the real-world rollover crash studies [21]. The upper neck injury indexes, including the neck $M_{x}$, neck $F_{y}$, and neck $\mathrm{F}_{\mathrm{z}}$ (Figures 10-12), were all improved. The maximum values of the neck $M_{x}$ and neck $F_{z}$ of the With-CAB case were reduced significantly.

After introducing the curtain airbag, the head's relative displacement toward B-pillar was reduced and its hard contact with B-pillar/roof rail could be avoided as well, as shown in Figure 13. This could also explain the reduction of head resultant acceleration for the With-CAB case around $225 \mathrm{~ms}$, as shown in Figure 8.

In addition, the simulation result showed that the head's position remained around the medium position relative to the headrest with the support of $\mathrm{CAB}$, and the distance between the head to the vehicle interior was increased, which was beneficial for the contact force reduction between the head and the interior. This explained that the head acceleration at $1090 \mathrm{~ms}$ was decreased dramatically for the With-CAB case.

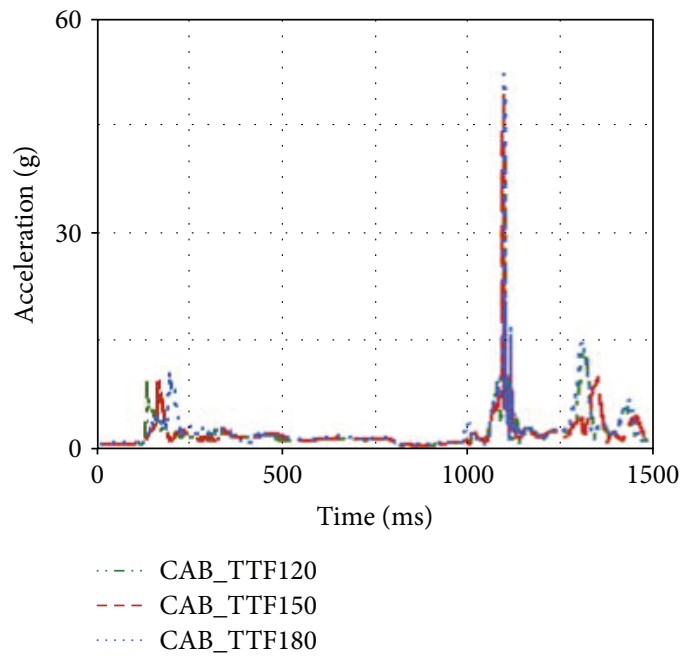

Figure 14: Head accelerations of different TTFs.

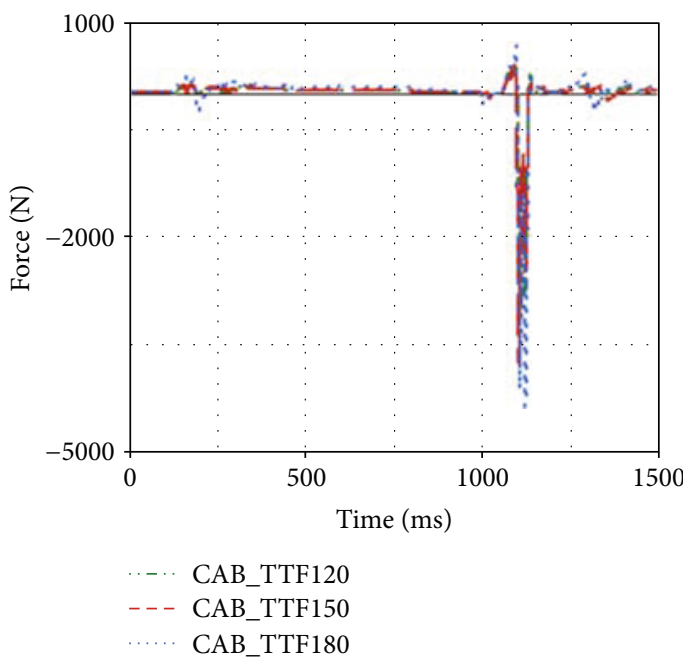

Figure 15: Upper neck $\mathrm{F}_{\mathrm{z}}$ of different TTFs.

3.3. The Influence of CAB Time to Fire (TTF) on Occupant Injuries. According to the kinematics of occupant in the No-CAB case, it was found that there was a contact between the head and B-pillar/roof at $225 \mathrm{~ms}$. Usually, the CAB inflation time was about $35 \mathrm{~ms}$. The ideal CAB TTF was that the head made contact with the $\mathrm{CAB}$ after it was full deployed. Thus, the CAB TTF was advised to set before 
TABLE 2: Occupant injuries with different airbag inflators.

\begin{tabular}{lcccccc}
\hline Number & Maximum pressure $(\mathrm{kPa})$ & Head acceleration $(\mathrm{g})$ & Chest acceleration $(\mathrm{g})$ & $\mathrm{Neck} \mathrm{F}_{\mathrm{y}}(\mathrm{N})$ & $\mathrm{Neck} \mathrm{F}_{\mathrm{z}}(\mathrm{N})$ & $\mathrm{Neck} \mathrm{M}_{\mathrm{x}}(\mathrm{Nm})$ \\
\hline CASE1 & 220 & 51.44 & 33.28 & -472.71 & -4006.11 & 18.82 \\
CASE2 & 245 & 49.52 & 30.51 & -492.57 & -3766.48 & 22.08 \\
CASE3 & 260 & 46.73 & 29.43 & -541.78 & -3467.94 & 26.13 \\
\hline
\end{tabular}

$190 \mathrm{~ms}$. Considering the margin value, TTF earlier than $180 \mathrm{~ms}$ was suggested.

After the TTF estimation above, three simulation cases with different CAB TTF settings were designed to evaluate such parameter's effects upon occupant injuries. The simulation results were listed in Table 1.

From Table 1, it was found that head acceleration and chest acceleration were increased when CAB TTF was increased from $120 \mathrm{~ms}$ to $180 \mathrm{~ms}$. Besides, the neck injury indexes were also increased. This was because the head displacement toward the B-pillar was reduced due to earlier CAB TTF. In the rollover, an earlier CAB TTF setting could result in earlier contact between the head and $\mathrm{CAB}$. Thus, an earlier CAB TTF setting could make the head acceleration of the first contact occur earlier, as shown in Figure 14.

Earlier contact between the head and CAB would affect the neck injury indexes as well. Compared with that of CASE2, the upper neck $\mathrm{F}_{\mathrm{z}}$ of CASE1 was reduced by $659.41 \mathrm{~N}$, as shown in Figure 15.

3.4. The Influence of $C A B$ Inflator Pressure on Occupant Injuries. The maximum pressure of inflator is a key factor for the $\mathrm{CAB}$ design. Three inflators with different maximum pressure were introduced in the simulation model for the following analysis. The simulation results were listed in Table 2.

According to Table 2, head acceleration, chest acceleration, and neck $\mathrm{F}_{\mathrm{z}}$ were reduced when the maximum pressure of $\mathrm{CAB}$ inflator was increased from $220 \mathrm{kPa}$ to $260 \mathrm{kPa}$. By contrast, neck $F_{y}$ and neck $M_{x}$ were increased when the maximum pressure of $\mathrm{CAB}$ inflator was increased.

In general, the increase of $\mathrm{CAB}$ inflator pressure could result in more support to the occupant and larger contact force between the head and CAB. In this rollover case, the neck $\mathrm{F}_{\mathrm{y}}$ and neck $\mathrm{M}_{\mathrm{x}}$ were increased when the $260 \mathrm{kPa}$ inflator was used. However, larger inflator made the head and chest regions move away from the B-pillar. The accelerations of the head and chest were reduced (see Figure 16), while the neck $\mathrm{F}_{\mathrm{z}}$ was also reduced when larger inflator was applied in the simulation model (see Figure 17).

3.5. The Influence of $C A B$ Protection Area on Occupant Injuries. Three types of $\mathrm{CAB}$ design with different protection areas were proposed to analyze the influence of the $\mathrm{CAB}$ protection area on occupant injuries, as shown in Figure 18.

CASE1 was the original CAB design. CASE2 was modified from CASE1, in which the thickness of frontal areas was reduced by the airbag suture. In CASE2, the position of airbag suture was $150 \mathrm{~mm}$ far from the head contact area. While for CASE3, the position of airbag suture was in the area of the head contact.

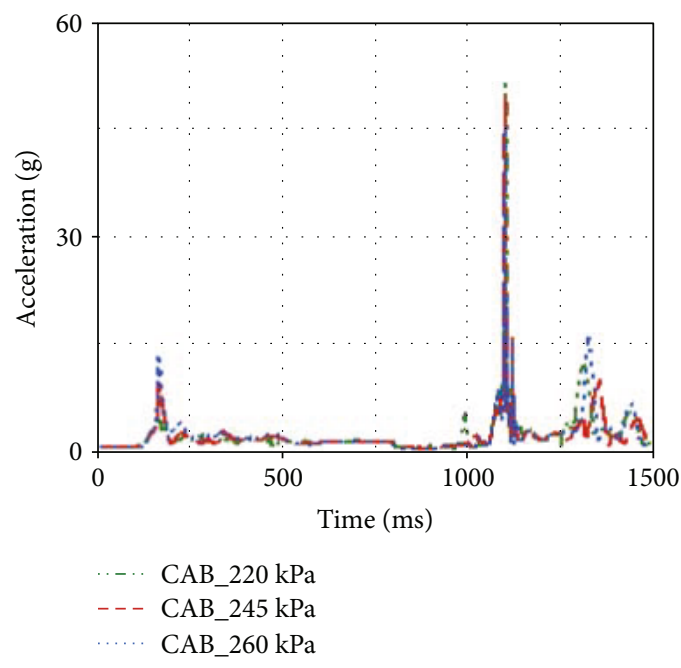

FIGURE 16: Head accelerations of different inflators.

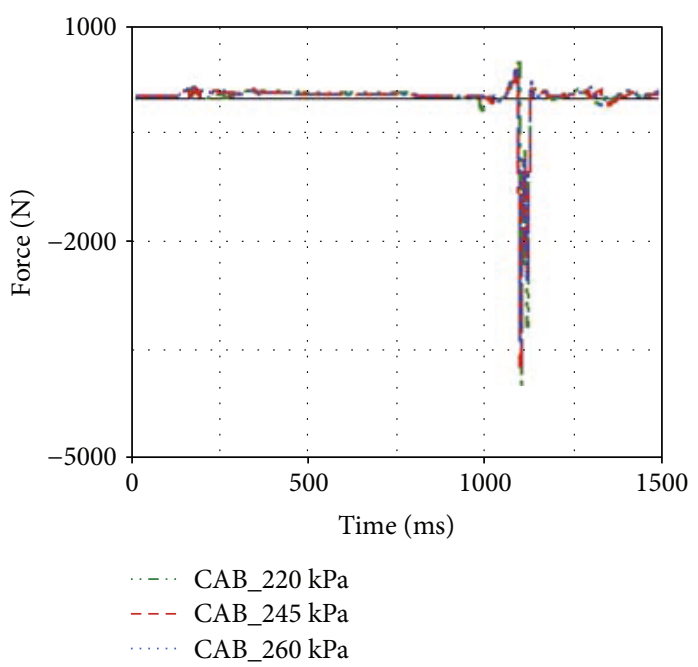

FIgURE 17: Upper neck $F_{z}$ of different inflators.

Three types of $\mathrm{CAB}$ were introduced to simulation model, and the simulation results were shown in Table 3.

It was found that the head acceleration was improved when the CASE3 CAB was used (see Figure 19). Neck injury indexes for the CASE3 were reduced as well, especially for the neck $F_{z}$, which was reduced by $1194.71 \mathrm{~N}$ (see Figure 20).

From the above analysis, it could be seen that the $\mathrm{CAB}$ design parameters, including the TTF setting, inflator data, 


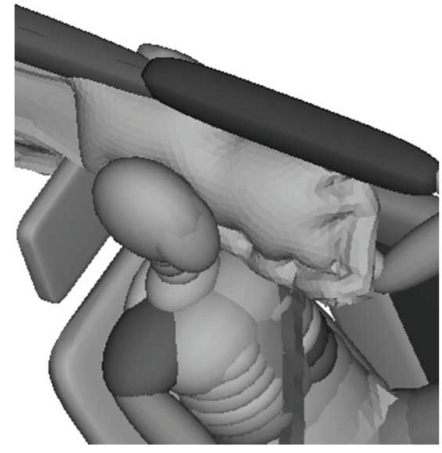

(a) CASE1

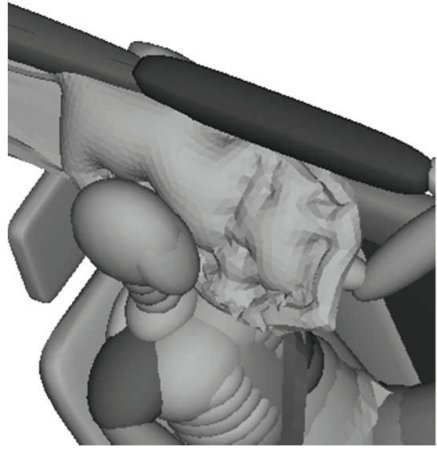

(b) CASE2

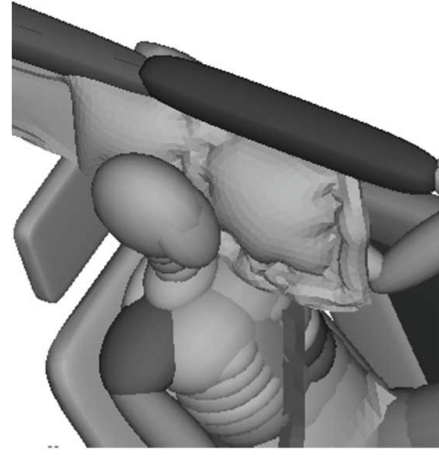

(c) CASE3

Figure 18: Three types of CAB with different protection areas.

TABLE 3: Occupant injuries with three types of CAB.

\begin{tabular}{lccccc}
\hline Number & Head acceleration $(\mathrm{g})$ & Chest acceleration $(\mathrm{g})$ & Neck $_{\mathrm{y}}(\mathrm{N})$ & Neck $_{\mathrm{z}}(\mathrm{N})$ & $\mathrm{Neck}_{\mathrm{x}}(\mathrm{Nm})$ \\
\hline CASE1 & 49.52 & 30.51 & -492.57 & -3766.48 & 22.08 \\
CASE2 & 47.29 & 29.46 & -423.21 & -3682.75 & 21.83 \\
CASE3 & 42.67 & 25.28 & -414.56 & -2571.77 & 17.26 \\
\hline
\end{tabular}

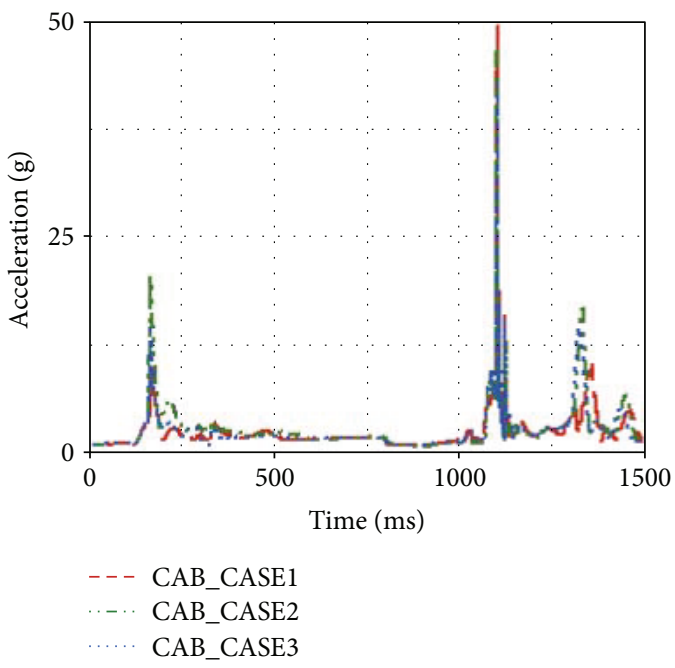

Figure 19: Head accelerations of different designs.

and protection area (or airbag thickness), are critical for the improvement of occupant kinematics and injury indexes in such rollover crash, which need detailed concern for certain vehicle restraint system design.

\section{Discussions}

The effects of $\mathrm{CAB}$ on occupant injuries were mainly on the occupant head region, as well as the neck and thorax regions. After introducing a validated $\mathrm{CAB}$ module, the maximum head resultant acceleration was reduced from $91.60 \mathrm{~g}$ to $49.52 \mathrm{~g}$. This was not only because CAB served as an energy absorbing object, but also it improved the occupant's

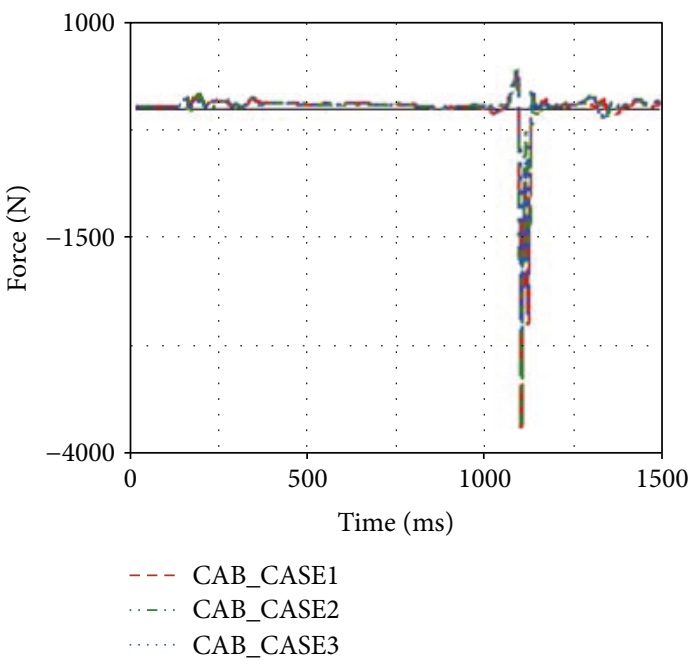

Figure 20: Upper neck $\mathrm{F}_{\mathrm{z}}$ of different designs. upregion kinematics. As shown in Figure 13, the head's relative displacement toward B-pillar was reduced and its hard contact with B-pillar/roof rail was avoided as well in this case. Avoiding hard contact is critical for the occupant protection in the rollover crashes, which was pointed out in the research of [11] as well. Introducing $\mathrm{CAB}$ can help reduce the head acceleration and, therefore, decrease the head injury possibilities as in the research of [22].

For the influence of CAB TTFs on occupant injuries, it was found that the earlier TTF setting (between $120 \mathrm{~ms}$ to $180 \mathrm{~ms}$ ) could reduce occupant injuries. However, TTF setting has to cooperate with rollover sensor calibration as well as the pressure holding capability of the $\mathrm{CAB}$, since the $\mathrm{CAB}$ 
pressure powered by a hybrid inflator usually reaches its peak around $40 \mathrm{~ms}$ and starts to decay afterwards [23].

In the actual design process, study on the inflator selection needs to be conducted for the balanced curtain airbag design. The maximum pressure of the inflator and pressure holding capability of the $\mathrm{CAB}$ need to be considered for both system and the component requirements.

Except the CAB TTF setting, pressure of the inflator, and protection area, there are still some other parameters that need to be optimized in further study, such as the pressure holding capability and $\mathrm{CAB}$ tether, as well as the friction coefficients of airbag fabric [13]. All these parameters need to be analyzed in the follow-up studies.

\section{Conclusions}

In this study, a multibody rollover simulation model of SUV was developed according to the physical test. The vehicle kinematics from the simulation correlated very well with that of the rollover test. Based on the validated model, a validated curtain airbag was imported and its main parameters' effects on occupant kinematics and injury indexes were evaluated.

Upon the above analysis, the following conclusions could be drawn:

(i) In this rollover case study, the main injury source for the case without curtain airbag was the contact with the vehicle interior. Introducing the curtain airbag could improve the occupant kinematics and upbody injury indexes, although the left arm was ejected in this case.

(ii) CAB design parameters, including the TTF setting, inflator data, and protection area, could affect certain injury indexes significantly. Among which, the TTF setting had the largest effect on the head acceleration. The maximum head acceleration was reduced $8.6 \mathrm{~g}$ after changing the TTF from $180 \mathrm{~ms}$ to $120 \mathrm{~ms}$. The neck $\mathrm{F}_{\mathrm{z}}$ could be decreased from $3766.48 \mathrm{~N}$ to $2571.77 \mathrm{~N}$ after the optimization of $\mathrm{CAB}$ protection area.

(iii) For this rollover case study, it was advised to optimize the curtain airbag thickness around the head contact area, for the reduction of the head and neck injury indexes.

\section{Conflicts of Interest}

The authors declare that they have no conflict of interest.

\section{Acknowledgments}

In this study, the authors would like to thank the support from the Key Laboratory of Advanced Manufacture Technology for Automobile Parts (Chongqing University of Technology), Ministry of Education Project (no. 2016KLMT03), and National Natural Science Foundation of China (Grant no. 51405050).

\section{References}

[1] A. de Lima and R. J. Marczak, "Simulating occupant injury in rollover crashes. Part 1: a numerical comparison of design procedures for vehicle roof strength assessment," International Journal of Crashworthiness, vol. 20, no. 1, pp. 78-94, 2014.

[2] NHTSA, Traffic Safety Facts 2012. A Compilation of Motor Vehicle Crash Data from the Fatality Analysis Reporting System and the General Estimates System, U.S. Department of Transportation DOT HS 812 032, Washington, D.C., USA, 2012.

[3] Traffic management bureau of the public security ministry, Traffic Safety Facts, Traffic management bureau of the public security ministry, Jiangsu, 2015.

[4] M. Yi, "China domestic car, MPV, SUV market sales in 2016," Jiao Che Hang Qian, vol. 2, pp. 32-33, 2017.

[5] T. Kim, J. Taewung, V. B. Crandall, R. Tarigala, and M. Guerrero, "Rollover initiation simulations for designing rollover initiation test system (RITS)," in SAE World Congress, pp. 68-69, Detroit, Michigan, USA, 2014.

[6] R. Grzebieta, M. Bambach, A. S. Mcintosh, K. Digges, and G. Mattos, "Replicating real world rollover crash injuries," in Proceedings 23rd International Technical Conference on the Enhanced Safety of Vehicles, pp. 13-0098, Seoul, Korea, 2013.

[7] M. Heller, S. Sharpe, W. Newberry et al., "Occupant kinematics and injury response in steer maneuver-induced furrow tripped rollover testing," SAE International Journal of Transportation Safety, vol. 3, no. 2, pp. 164-215, 2015.

[8] B. Han and J. H. Seo, "Analysis of vehicle rollover using multibody dynamics," Journal of Mechanical Science and Technology, vol. 30, no. 2, pp. 797-802, 2016.

[9] C. Jiang, C. E. Neal-Sturgess, and Y. Hu, "Kinematics simulation and head injury analysis for rollovers using MADYMO," International Journal of Crashworthiness, vol. 15, no. 5, pp. 505-515, 2010.

[10] G. A. Mattos, R. H. Grzebieta, M. R. Bambach, and A. S. Mcintosh, "Head injuries to restrained occupants in single vehicle pure rollover crashes," Traffic Injury Prevention, vol. 14, no. 4, pp. 360-368, 2013.

[11] M. R. Bambach, R. H. Grzebieta, A. S. Mcintosh, and G. A. Mattos, "Cervical and thoracic spine injury from interactions with vehicle roofs in pure rollover crashes," Accident Analysis \& Prevention, vol. 50, pp. 34-43, 2013.

[12] W. N. Newberry, S. Imler, M. Carhart, A. Dibb, K. Balavich, and J. Croteau, "Belted occupant kinematics and head excursion during the airborne phase of vehicle rollover: evaluation of the effects of rollover-deployed curtain airbags," SAE Technical Papers, vol. 1, no. 3, pp. 211-214, 2014.

[13] National Highway Traffic Safety Administration, "Updated estimates of fatality reduction by curtain and side air bags in side impacts and preliminary analyses of rollover curtains," Annals of Emergency Medicine, vol. 65, no. 2, pp. 218-219, 2015.

[14] TASS, MADYMO 7.5, User Manual, TASS, Helmond, 2013.

[15] J. R. Kerrigan, A. Jordan, D. Parent et al., "Design of a dynamic rollover test system," SAE International Journal of Passenger Cars-Mechanical Systems, vol. 4, no. 1, pp. 870-903, 2011.

[16] National Crash Analysis Center and The George Washington University, Ford Explorer, National Crash Analysis Center and The George Washington University, Washington, D.C., USA, 2007. 
[17] C. Jiang and C. E. Neal Sturgess, "A study of the simulation of a front-crash-induced rollover crash," Proceedings of the Institution of Mechanical Engineers, Part D: Journal of Automobile Engineering, vol. 221, no. 12, pp. 1487-1497, 2007.

[18] D. F. Huelke, J. Marsh, and W. Ballard, "Injury causation in rollover accidents," in Proceedings of the 17th Conference of the American Association of Automotive Medicine, pp. 87115, Oklahoma, USA, 1973.

[19] K. Digges and A. C. Malliaris, Crashworthiness Safety Features in Rollover Crashes, SAE Technical Paper 982296, Warrendale, Pennsylvania, USA, 1998.

[20] D. Mihora, K. Friedman, and J. Hutchinson, "Effect of friction between head and airbag fabric on ejection mitigation performance of side curtain airbag systems," in SAE World Congress, Detroit, Michigan, USA, 2011.

[21] K. Digges, A. Malliaris, and H. DeBlois, "Rollover injury causation and reduction," in Proceedings of the 26th International Symposium on Automotive Technology and Automation, pp. 681-685, Aachen, 1993.

[22] F. Li, H. Li, Z. Xiao et al., "A review on injury mechanism of intracerebral hemorrhage in vehicle accidents," Current Pharmaceutical Design, vol. 23, no. 15, pp. 2177-2192, 2017.

[23] B. Feng, "CAE applications for balanced curtain airbag design meeting FMVSS226 and system/component performance," in Proceedings of the 13th International LS-DYNA Users Conference, pp. 1-10, Detroit, Michigan, USA, 2014. 


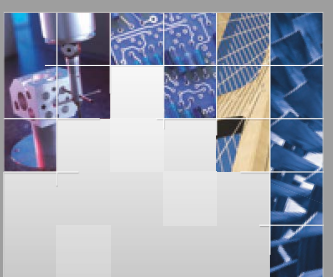

\section{Enfincering}
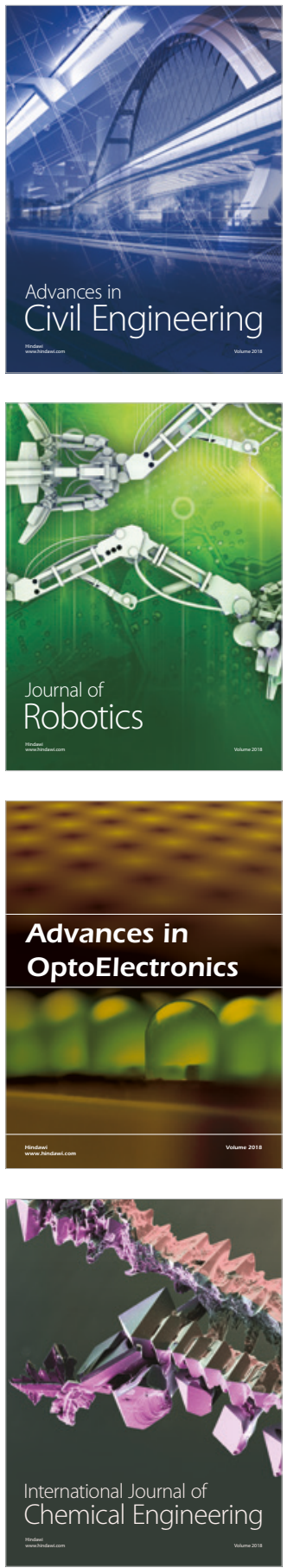

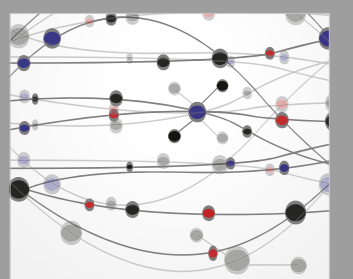

\section{Rotating \\ Machinery}

The Scientific World Journal

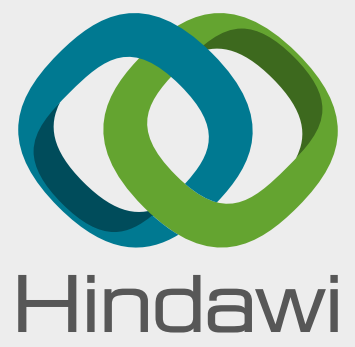

Submit your manuscripts at

www.hindawi.com
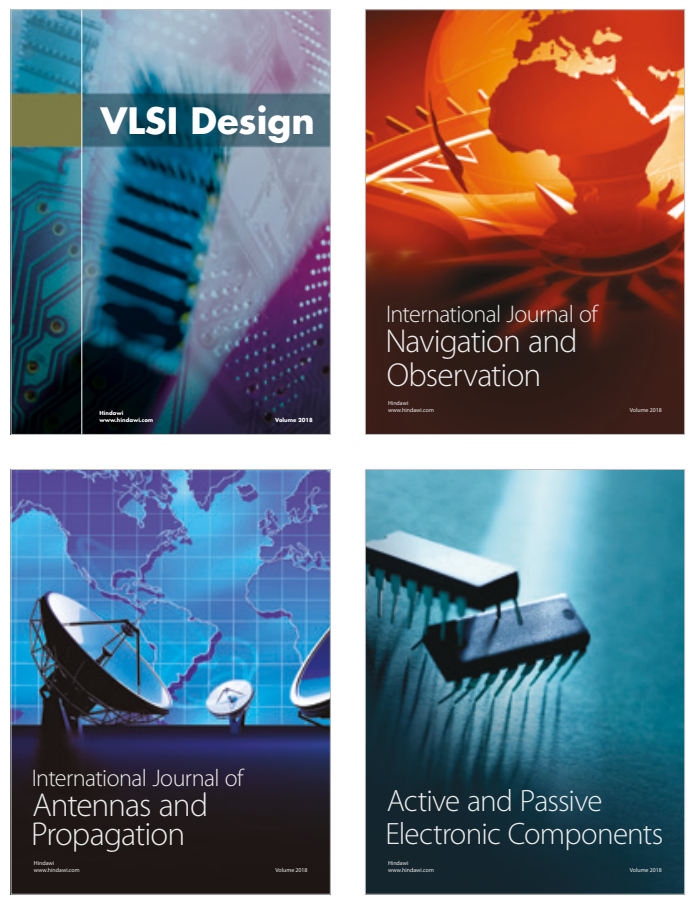
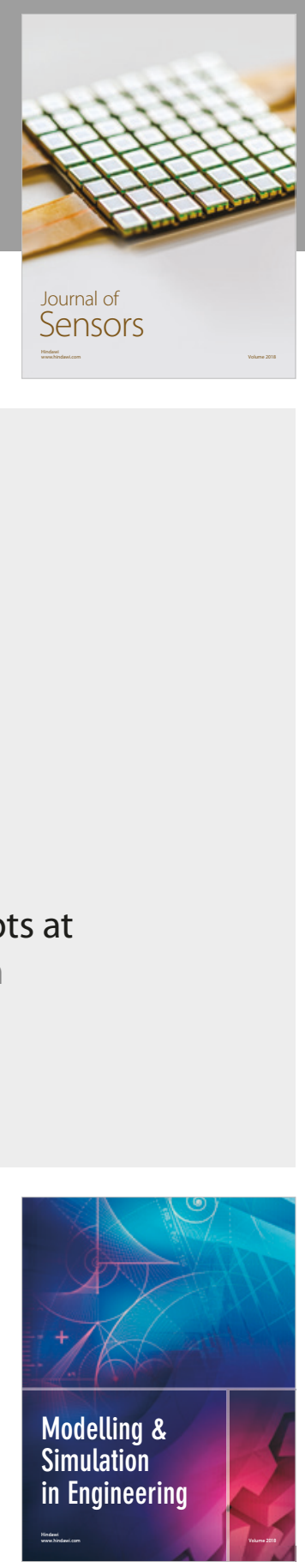

\section{Advances \\ Multimedia}
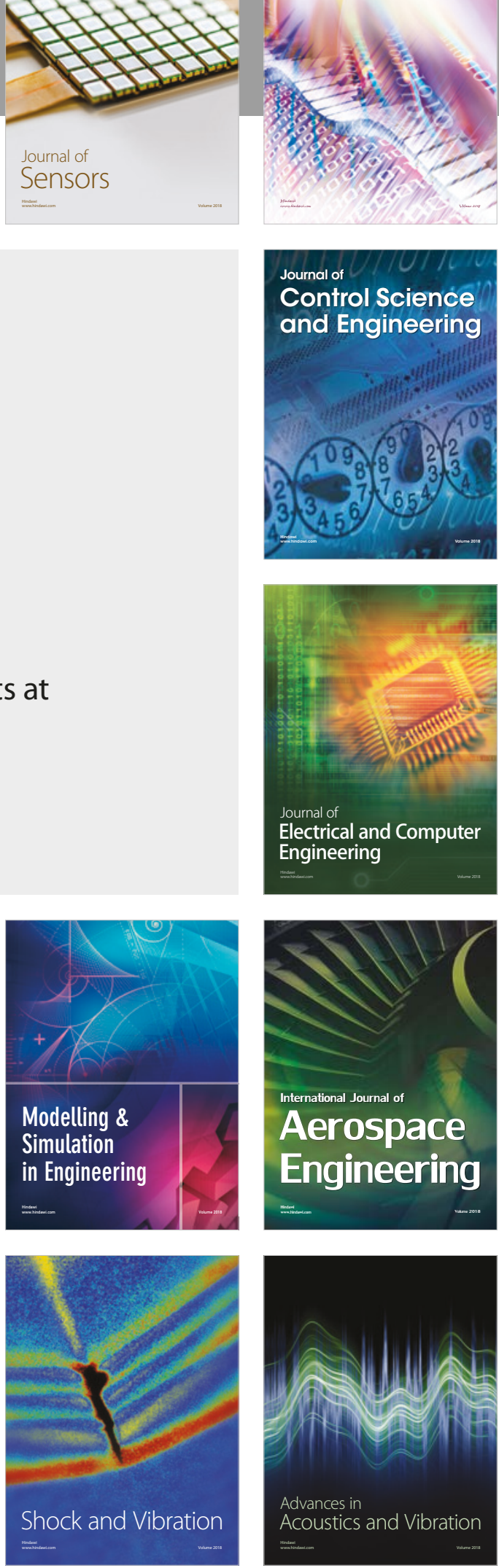